\title{
COVID-19 in Adults and Children, Symptoms and
}

\section{Treatment}

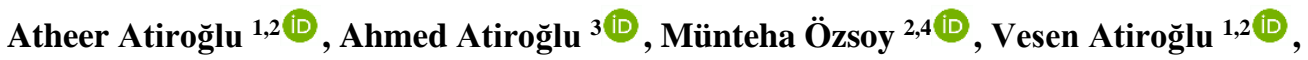 \\ Mahmut Özacar 2,4,* (D) \\ 1 Sakarya University, Biomedical, Magnetic and Semiconductor Materials Application and Research Center (BIMAS-RC), \\ 54187, Sakarya, Turkey \\ 2 Sakarya University, Biomaterials, Energy, Photocatalysis, Enzyme Technology, Nano \& Advanced Materials, Additive \\ Manufacturing, Environmental Applications and Sustainability Research \& Development Group (BIOENAMS R\&D \\ Group), 54187 Sakarya, Turkey \\ 3 Sakarya University, Faculty of Medicine, 54290, Sakarya, Turkey \\ 4 Sakarya University, Science \& Arts Faculty, Department of Chemistry, 54187, Sakarya, Turkey \\ * Correspondence: mozacar@hotmail.com (M.O.);
}

Scopus Author ID 6603796256

Received: 21.04.2021; Revised: 20.05.2021; Accepted: 23.05.2021; Published: 10.06.2021

\begin{abstract}
The COVID-19 is quickly spreading globally, and the number of cases in Europe and the United States is highly increasing. Compared to diseases caused by earlier identified human CoVs, COVID-19 displays higher transmission competence with minimal severe pathogenesis, as is obvious from the unceasingly increasing numeral of confirmed cases. Older adults with diabetes, respiratory disease, cardiovascular disease, etc., are more likely to be infected with COVID-19, and COVID-19 disease affects older adults with underlying chronic conditions more than other age groups. Comorbidities are known to aggravate the course of COVID-19 and increase the risk of death associated with COVID-19. However, one factor that makes it difficult for older adults to fight infection is that they have a weaker immune system than other individuals. Another group that the new coronavirus, SARS-CoV-2, could infect is children. However, they seem to be lesser sensitive to infections than adults, and COVID-19 symptoms are usually milder. There are currently no scientific data with a sufficient level of evidence regarding the treatments for COVID-19 infection in children. Therefore, COVID-19 for children's treatment recommendations should be evaluated according to adult studies and pediatric patients. We highlight the diagnostic, clinical, epidemiological, radiological characteristics laboratory and treatment in adults and children in the present study.
\end{abstract}

Keywords: adult; child; COVID-19; viruses; ACE2; treatment.

(C) 2021 by the authors. This article is an open-access article distributed under the terms and conditions of the Creative Commons Attribution (CC BY) license (https://creativecommons.org/licenses/by/4.0/).

\section{Introduction}

Viruses of the coronaviruses family may reason a series of disorders in individuals, from the common cold to SARS [1]. It is a family of viruses that can give rise to lung infection [2]. According to the WHO, viral infections remain to arise and characterize a thoughtful problem to health in the world. Among viral-borne outbreaks, severe acute respiratory syndrome coronavirus (SARS-CoV) in the 2002-2003 period and H1N1 influenza virus seen in 2009 were enrolled [3]. A new strain of coronaviruses with significant pathogenicity in animals and humans was recognized as the cause of a group of pneumonia cases in China at the end of 2019 [4,5]. It quickly became widespread in China, began to be seen in different world countries, and increased the number of patients day by day. In February 2020, WHO 
defined the 2019 coronavirus disease as COVID-19 disease [6]. Extensive biochemical and morphological alterations happen in the infected cells of coronavirus (CoV) [7]. Infection by different COVID-19 causes modifications in the translation and transcription patterns, cytoskeleton, apoptosis, and cell cycle of the host cell. Besides, COVID-19 infection may cause inflammation and stress responses [8]. A continuous outbreak of pneumonia is still ongoing, linked with a new coronavirus, also known as SARS-CoV-2 or COVID-19 [9]. Although inaccessibility in the primary period and a high level of false negativity of the RT-PCR assay limit the rapid diagnosis of patients, RT-PCR continues to be the method of detecting COVID19 infection [10]. COVID-19 infection has been noted as having the potential to cause disease in all age groups, including the elderly, young adults, children, and infants. Children under the age of 18 account for only $2 \%$ of total cases worldwide. Research has reliably shown that children are not the most affected group of this epidemic, but they still run the risk of being among the biggest injured. Fortunately, so far, COVID-19 has largely recovered from direct health impacts, although the crisis has had a profound impact on well-being. This universal crisis, which will last for a lifetime for some children, has affected all countries, especially socio-economic effects, and in some cases, mitigation measures that can give more damage than beneficial by accident have shaped the course of the disease [11]. The first question to ask when discussing how children are affected by this pandemic is whether they can get infected and, if so, how much. As of late April, only 2,572 (1.7\%) of the 149,082 confirmed COVID19 cases in the US were infants, despite children formed $22 \%$ of the US population. However, the last literature suggests that physiologically, children are as probable as adults to be infected with SARS-CoV-2. This difference in case levels and biological vulnerability may be attributed to the reality that children usually have low to moderate symptoms when infected by the coronavirus and are often less likely to get checked. It may also be because children have had less exposure to the virus relative to adults in general. Kids are not going to college, they are typically going out to shops fewer than adults, and they are not going out to bars or gyms in the states that have eased quarantine measures [12].

The current study aimed to explain symptoms clinical, epidemiological, laboratory, radiological characteristics, and therapy of patients infected by COVID-19. We hope that the present study returns will acquaint many people in the world with the appearance of the COVID-19 infection and its clinical features.

\section{Symptoms and Observation of Coronavirus}

The main Covid-19 symptoms are cough, weakness, fever, and shortness of breath, as well as symptoms such as sore throat, malaise, joint-muscle pain, which can be seen in other viral infections. It is known that starting treatment early in viral infections plays a significant role in achieving treatment. Therefore, if the patients have symptoms and known contact history during the epidemic period, it is recommended to start hydroxychloroquine according to the patient's clinical, laboratory, and radiological findings without waiting for the PCR result. In Covid-19 disease, treatment planning should be done according to the severity/intensity of the disease, and if there is a progression in symptoms and signs in the follow-up, treatment changes should be made. According to this situation, the patients to be treated can be grouped as mild/outpatient follow-up-treatment patients, moderate-heavy/hospitalized patients, and very severe patients whose clinic worsens. In each patient's treatment, the decision must be made according to the patient's specific condition, and comorbid diseases accompanying must 
be considered. This is more probable to occur in and people with weakened immune systems, the elderly, and children [13].

Children's symptoms tend to be milder and slightly different from those of adults. Diarrhea and/or vomiting are seen at a rate of approximately $10 \%$, and runny nose or sore throat in 30-40\% from upper respiratory tract symptoms in children compared to adults. Only half of the symptomatic children have less cough or fever than adults. Adolescents and even very young children can acquire COVID-19. There are plenty of them who have no symptoms. The general symptoms of many patients are fatigue, low fever, and cough, and these are considered mild symptoms. Children with pre-existing health problems may be at increased risk of serious illness [12]. Although children with major complications in the population have less spread, the disease course can be serious and dangerous in children with a more recent complication. This clinical picture, called a multisystem inflammatory syndrome, can cause life-threatening problems in the body's organs, especially in children's hearts. Initial reports compare multisystem disease in children with Kawasaki, an inflammatory disease that can cause heart problems, but some cases are very similar to Kawasaki, while others are found to be different. The following symptoms can be seen in multisystem inflammatory syndrome [14,15]:

- fever long-lasting more than a few days

- stomachache

- nervousness and/or abnormal slumber state of lassitude

- rash

- a tongue that is redder than normal and appears as strawberry

- red, cracked lips

- conjunctivitis (flush in the eye white part)

- diarrhea and/or vomit

- a great, swelled lymph knot in the neck

Many countries use clinical and epidemiological data to define who should test. According to the United States, COVID-19 patients have symptoms of fever and acute lung infection [16]. If a person is under investigation, the physicians directly put in place infection control and prevention precautions [17]. In Turkey, under 50 is considered to be unnecessary for hospitalization, the clinic is light, and the COVID-19 is heavy without risk factors (chronic lung disease, hypertension, diabetes, chronic kidney failure, heart disease, or immunity failure, etc.) definitive COVID-19 cases are appropriate, if necessary until symptoms clear. The treatment is started and followed at home. However, the patient's social indication (home conditions, a risk that may cause severe survival of $>65$ years of age and/or COVID-19 at home.

Individuals with a factor can be followed up in the hospital with the decision of the physician. Azithromycin should not be given because of its cardiotoxicity in patients to be monitored at home, but it can be possible in combination with hydroxychloroquine. Patients followed at home must be monitored by their family doctor up to they recover. Patient's medical information must be shared with the family doctor, and a consent form containing this information is signed after the patient is informed about what to do at home and criminal liability every day during the 14-day follow-up. The patient should spend the follow-up at home. Also, visitors to the home should not be accepted during the follow-up period. There are many unknown aspects of coronavirus that have not yet had a definitive treatment or vaccine. It is not known how it will affect the people who got and survive this disease in the long term. The 'COVID-19 Patient Monitoring Center' was opened by the Istanbul Medical Faculty to answer these questions. This center will investigate whether the coronavirus causes permanent 
damage in patients by performing various tests and examinations on those who got coronavirus and survive use should not be accepted. In the intensive care process, patients experience various problems, which need to be solved in the long term. For example, information has been shared in the literature that COVID infection causes disease in the pancreas and intestine and damage to these organs in the long term. It is stated that these patients will be prone to diabetes in the future and diseases such as celiac in the intestines. It is among the unknown issues that there are serious heart involvements in COVID-19 patients even a long-time after identification and whether cardiac involvement will progress in the long term or cause heart failure. 'COVID19 Patient Monitoring Center' aims to clarify these issues by following patients for 1 year about these unknown issues [18].

When the genetic material is adequate for parts of the conserved genetic code of COVID-19, the amplification of genetic material extracted from a saliva sample is performed by RT-PCR under laboratory conditions [16]. The studies used were established in the first gene sequence published by Fudan University, China, and then in evaluations approved by other laboratories [19]. In the COVID-19 patients, the laboratory estimate should be repeated to assess the clearance of the virus before secretion. The test result must be positive for the diagnosis of COVID-19, but if there is suspicion for COVID-19 even though the initial test was negative, WHO proposes resampling from various respiratory tract regions and repeating the test [20]. The correctness and estimated values of the COVID-19 test have not been systematically evaluated. Some reports have reported negative RT-PCR tests on oropharyngeal swabs, despite CT evidence suggesting viral pneumonia in some positive patients for COVID19 [21]. Test availability varies depending on the person who lives in which country, but reachability occurs almost daily [22].

Laboratory tests can detect a normal or decreased total WBC count and a low number of lymphocytes at the onset of the infection while increasing values of lactate dehydrogenase enzyme (LDH), C-reactive protein, and liver enzymes can be found. In critically ill patients, a decrease in blood lymphocytes and an increase in amylase level were observed, along with coagulation disorders. Currently, there are two accessible Covid-19 diagnostic forms. One test displays patient blood samples for antibodies against the virus. Conversely, antibodies are often not noticeable till several days after symptoms initiate. The alternative test detects viral DNA in a sputum sample. These investigations can identify the virus earlier in the infection, but they require several hours to complete. Chest computed tomography (CT), which has a significant role in diagnosing this infection disease, can detect the primary phase of lung infection and enable faster public health research [23-25]. By the industrialization of a new Covidi-19 test, Turkey's National Virology Laboratory will provide faster diagnosis. While diagnostic kits in France, the United Kingdom, and Germany do not yield results in less than three hours, the diagnosis time for a new kit is between $15 \mathrm{~min}$.

\section{Etiology}

Coronaviruses are enclosed positive and big RNA viruses that infect many birds and mammalian types, which cause enteric, neurological, gastrointestinal, and respiratory diseases [26]. Coronaviruses are four types: $\alpha, \beta, \gamma$, and $\delta$ [27]. These genera, a casing-attached spike protein, directs coronavirus access into host cells [28]. There are two different forms of spike: pre-fusion and post-fusion [29]. A pre-fusion state is a metastable form: $\mathrm{S} 2$ is prohibited from transition to post-fusion structure because of the structural restraints compulsory by S1. On the other hand, during the entry to the cell, the spike is cut successively by proteases enzyme in 
the host at two regions: first at the S1-S2 boundary and second within S2 [30]. After splitting, $\mathrm{S} 1$ detaches from S2, the S2 transitioning to the structure of the post-fusion. The transition process to post-fusion from pre-fusion is irreversible, and therefore this is a closely controlled process [31].

Each S1 subunit has a C-terminal domain (S1-CTD) as well as the N-terminal domain (S1-NTD). The S1-CTD known to identify the receptor of protein is found on the spike trimer [32]. Receptor linking stabilizes the S1-CTD in the standing-up modification, facilitating the dissociation of S1 from S2 and flagging the S1-S2 interactions [33]. Therefore, S1-CTD has a significant role in coronavirus entry: it regulates viral connection and enables membrane combination. In contrast, S1-NTD is accommodated on the flank of the spike trimer and generally identifies sugar receptors. To date, it has not been observed that S1-NTD undergoes any dynamic conformational alterations. Thus, it is unknown how S1-NTD has a role in activating the membrane fusion development, further than its recognized role in viral addition [34]. Shang J. et al. have prepared both mouse CEACAM1a ectodomain and MHV spike ectodomain (S-e) for cryo-EM studies. They made ready the MHV S-e in the pre-fusion status and removed the $\mathrm{C}$ terminal transmembrane and the intracellular queue of the MHV spike and substituted them with a GCN4 trimerization label and a His6 label. Recombinant MHV S-e molecules were frequently completed and had not been split by proteases. Consequently, the CEACAM1a recombinant MHV S-e were added and purified the complex (Figure 1) [35].
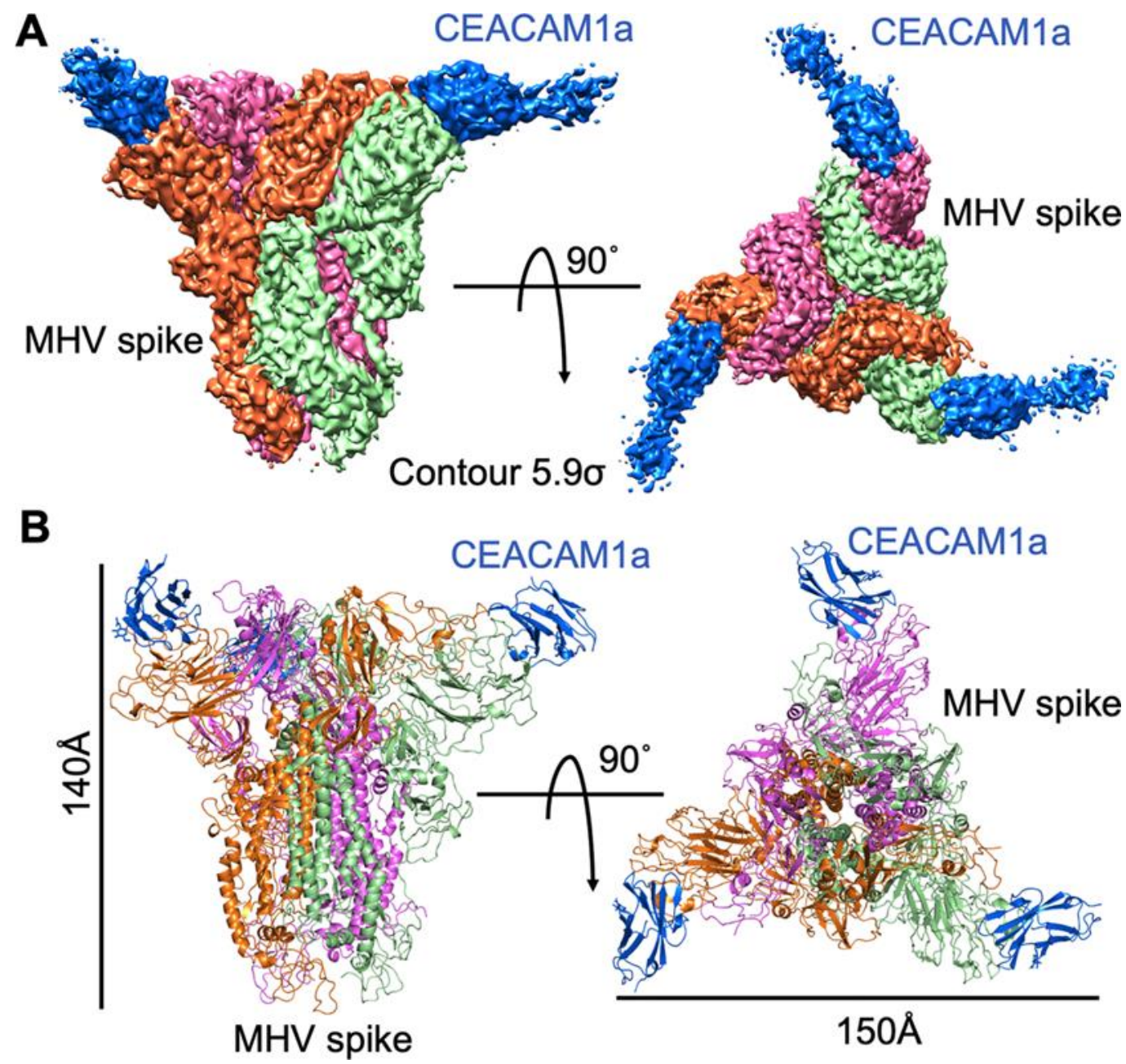

Figure 1. The complex of MHV spike protein/CEACAM1a. (A) Cryo-EM intensity map of MHV spike exodomain/CEACAM1a complex. The trimeric MHV spike exodomain (S-e) is in the prefusion status; (B) Atomic structure of MHV S-e/CEACAM1a complex [35]. 


\section{Histopathology}

To understand the cell membrane protein angiotensin converting enzyme 2 (ACE2) distribution in the brain of humans, the brain has been described to express the receptors of ACE2 as shown (Figure 2A, C), which identified the neurons and glial cells, which creates them a possible target of COVID-19. Another study showed the SARS CoV ability to mice death [36]. It is necessary to know the possible neurotrophic effect of COVID-19 in patients recently identified as the COVID-19 outbreak. In the previous report, an autopsy of SARS$\mathrm{CoV}$ infections revealed a strong indicator of SARS-CoV incidence with RT-PCR, electron microscopy, and immunohistochemistry [37]. The function of the blood-brain block having the virus and stopping contact with neural tissues requires additional study in COVID-19 patients. A study displayed in MedRxiv4 identified the neurological appearances in the COVID-19 pandemic and detailed 214 patients with neurological symptoms, confirming the basis of the neurotropic potential in $36.4 \%$ of these patients. Also, a study on a patient with involuntary loss of control with acute respiratory failure calls on healthcare professionals to separate patients with COVID-19 into neurologically affected cases. Like the SARS-CoV, the mRNA of the COVID-19 virus encoding several other proteins uses a spike protein S1 that supports the binding of the virion to the membrane of a cell by interacting with the host receptor of ACE2 (Figure 2C, D). The distribution of COVID-19 in the bloodstream at the first or late stage of the infection contributes to the cerebral contribution, as described for patients affected by SARS-CoV (Figure 2) [37]. The incidence of the COVID-19 virus in the bloodstream allows it to cross into the cerebral circulation, where the slow movement of blood in microcirculation can occur and ease the interplay of COVID-19 virus spike protein with ACE2 in the capillary endothelium. The endothelial lining is promising to promote the access of viral particles to the brain through the capillary endothelium after destruction (Figure 2B). After penetration into neuronal tissues, the coronavirus interface with ACE2 receptors is shown in (Figure 2C, D).

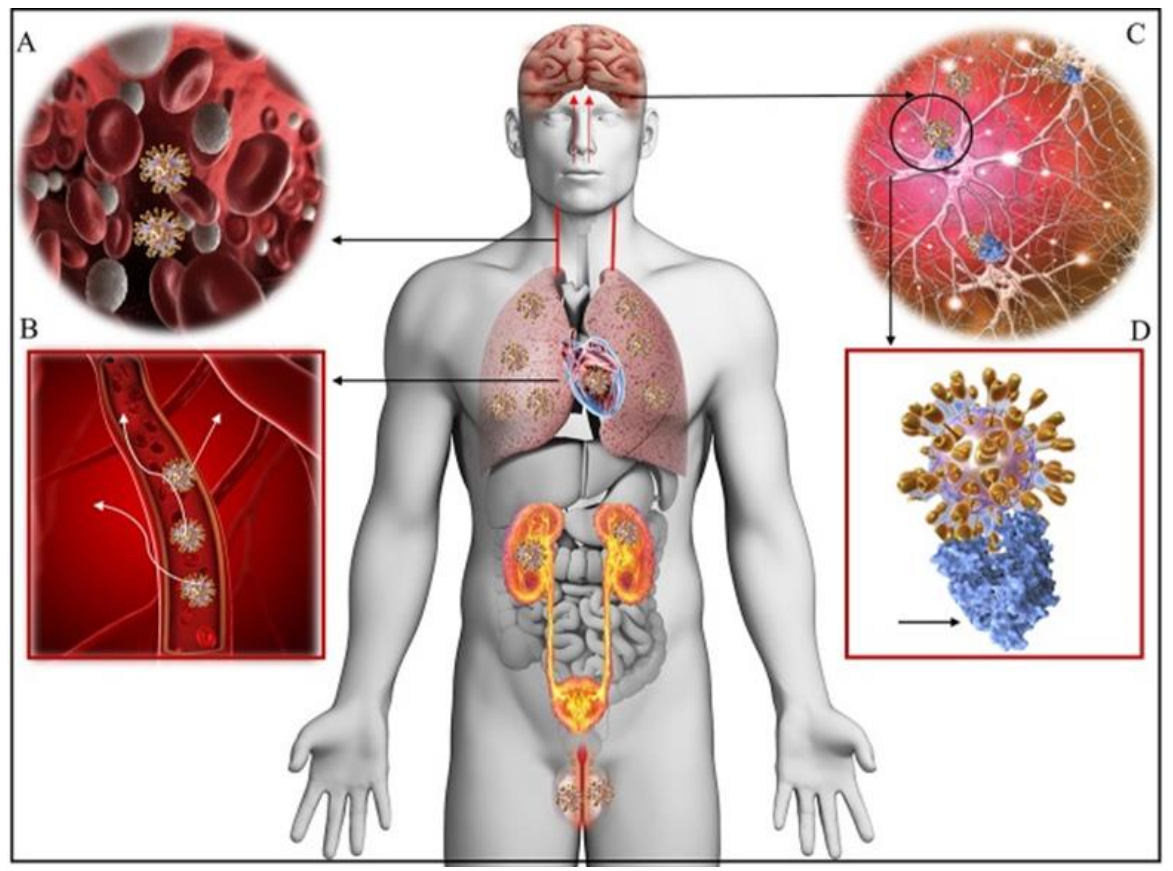

Figure 2. Humans' tissue distribution of the receptors of ACE2. (A) Circulates the COVID-19 virus through the bloodstream; (B) Neurotropic can take place by circulation that allows the COVID-19 to reach the brain; (C) and bind and involve with the receptors of ACE2, blue; (D) COVID-19 ports on the ACE2 through spike protein. Revealed are the heart, brain, kidneys, lungs, intestines, and testicles that are renowned for expressing ACE2 receptors and are probable targets of COVID-19 [37]. 
Another study has shown that COVID-19 is bound to the ACE2 surface by the S protein. The S protein cleaves into S1 and S2 subunits during infection. It lets coronaviruses link to the peptidase domain (PD) of ACE2, the receptor linking domain (RBD) at S1. It then plays a role in the fusion of the S2 membrane. When the ACE2 construct is bound to the ligands, the amino acid carrier B0AT1 can be linked to ACE2-B0AT1 (Figure 3). These structures have not been recognized so far and may help create antivirals or a vaccine to prevent coronavirus infection by targeting ACE2. The study suggests that ACE2's wishes to be active to weaken. The resulting homodimer contains two PDs capable of binding two COVID-19 S protein trimmers simultaneously [38]. Other studies confirm that COVID-19, S proteins form trimers by two of the RBDs opposite one way and the additional opposite the reverse way [39].
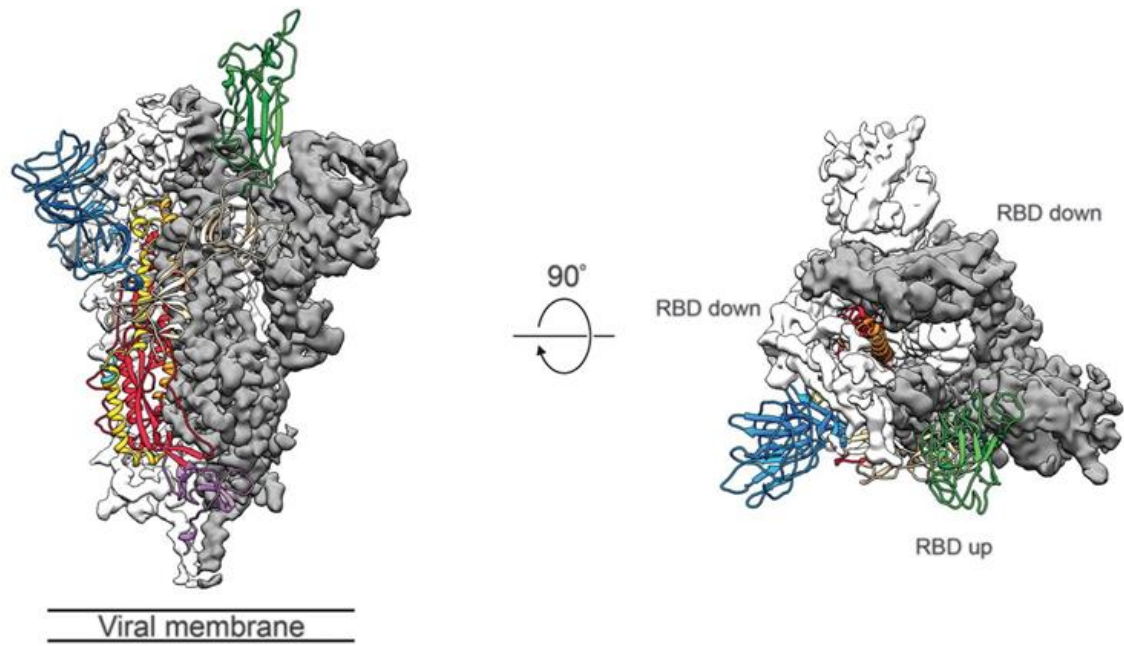

Figure 3. The ACE2 structure after binding to the classic ligands, the amino acid transporter B0AT1, and as well how the COVID-19 receptor-binding domain bind to the ACE2-B0AT1. The receptor-binding domain-up protomer is exposed in colored green. The RBD-down protomers are presented as cryo-EM density in either grey or white [39].

Yan et al. showed that the structures might be linked if the PD interrelates with the up RBD. The general structure of the RBD-ACE2-B0AT1 is shown in (Figure 4). The researchers established that a new investigation could give the designs of structure-based antibodies or ligands talented to target ACE2 or coronavirus spike proteins to inhibit the infection of the viral [40].

A

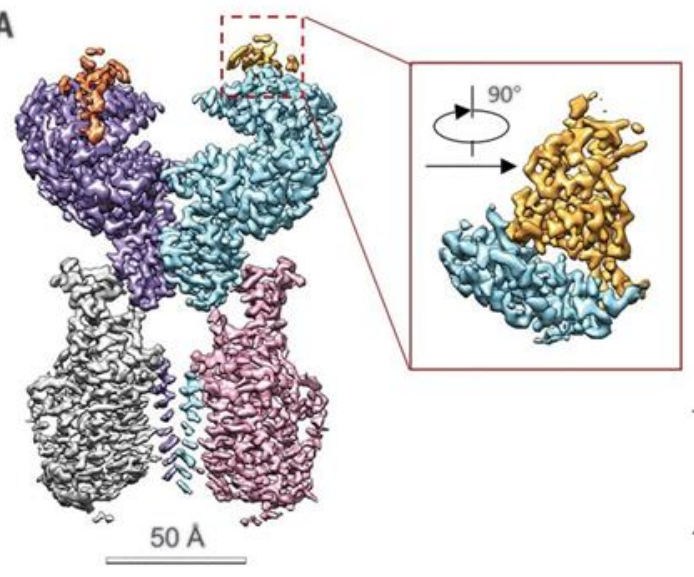

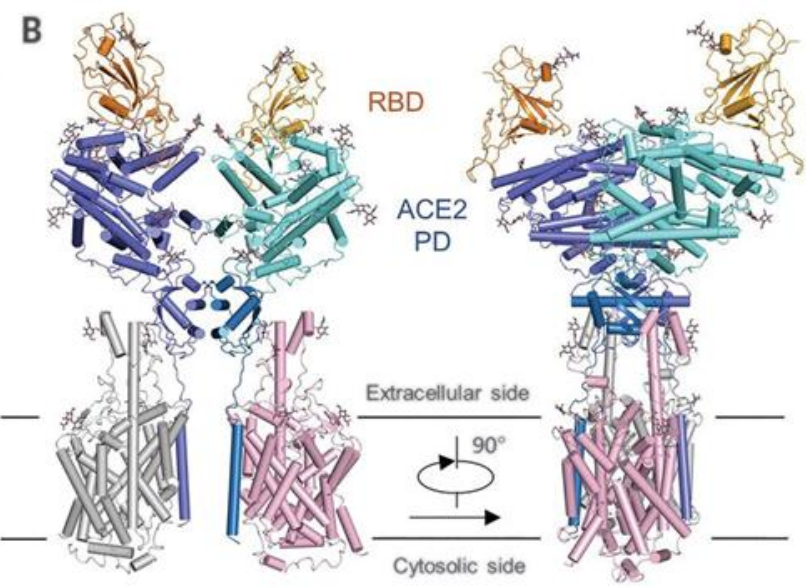

Figure 4. RBD-ACE2-B0AT1 structure. (A) Structure of Cryo-EM map of the RBD-ACE2-B0AT1; (B) The complex is stained with blue and blue colored subunits in the PD and Collectrin-similar domain ACE2 protomers. The SARS-CoV-2-RBD binding is unlike other SARS-CoV-RBDs bindings; display modifications in the sequence can create tighter connotations in COVID-19, whereas others might decrease the affinity of bindings [40]. 
Tian et al. showed histopathological statistics attained on the patient's lungs. Those who underwent lung lobectomy due to adenocarcinoma and who got the infection retrospectively during surgery. In addition to tumors, important proteinaceous were seen in the lungs of both "accidental" positions as edema and huge protein globules. Furthermore, the researchers described vascular occlusion with fibrinoid material, pneumocyte hyperplasia, and inflammatory groups of multi-nucleus giant cells [41].

Actually, children have a lesser possibility of displaying symptoms when infected with SARS-CoV-2 raises doubts and worries that they can be responsible for latent virus contagion, but there is little direct proof that asymptomatic children contribute to the spread of the virus disease. Research analyzing the source of the 31 households COVID-19 cluster in Singapore, China, Iran, South Korea, and Japan found that children were the infection source in only three of these positions [13].

The China/WHO joint commission, a group of international experts investigating the first COVID-19 outbreak in China, detected no cases of contagion from a child to an adult through contact tracing [42]. The early closure of schools and the markedly reduced susceptibility of children to infection have been accepted as indicators that transmission from children may be limited. More studies are needed to test the idea that "the absence of cough in milder or asymptomatic cases may reduce the transmission of the virus". Although the impact of children on the transmission of the virus is not fully known, evidence suggests that children are less likely to become infected and have a lower probability of infecting family members in the home than adults [42].

\section{Treatment}

At now, there is no specified antiviral drug for the definitive therapy of COVID-19, and the vaccine is currently not efficiently accessible to all countries of the world. The cure is symptomatic, and the main course of action for patients who possess severe infections is oxygen treatment. While mechanical ventilation may be required in the case of respiratory failure resistant to oxygen treatment, hemodynamic support is required to regulate septic shock, according to WHO guidelines, infection prevention and control plans; initial adjuvant therapy and monitoring; a guide for laboratory diagnosis; administration of respiratory failure and acute respiratory distress syndrome (ARDS); prevention of complications; therapies; and thoughts for pregnant patients.

\subsection{Intubation and protective mechanical ventilation.}

Different preventions are required throughout intubation. A specialist worker must perform the process using personal protective equipment, such as safety glasses, disposable pair of socks, N95 mask, and gloves. Preoxygenation ( $100 \% \mathrm{O}_{2}$ for $5 \mathrm{~min}$ ) should be done by the continuous positive airway pressure method. Mechanical ventilation must be done with low tidal volumes and low inspiratory pressures. To keep driving pressure (Pplat-PEEP) as low as possible, the positive end-expiratory pressure must be as high as possible $\left(<14 \mathrm{~cm} \mathrm{H} \mathrm{H}_{2} \mathrm{O}\right)$. Also, breaks from the ventilator should be avoided to prevent PEEP and atelectasis loss. Finally, paralysis is not proposed unless $\mathrm{PaO} 2 / \mathrm{FiO} 2<150 \mathrm{mmHg}$. The protective fluid management strategy using is emphasized for ARDS patients without tissue hypoperfusion. 


\subsection{Noninvasive ventilation.}

Regarding noninvasive ventilation, the panel of experts states that these methods achieved by schemes with appropriate interfaces do not constitute a large dispersion of exhaled air, and their use may be explained to be low in airborne risk [43]. Practically, noninvasive methods can be used in non-severe forms of respiratory failure. But, if the current situation does not increase or even improve within 1-2 h, mechanical ventilation should be chosen.

\subsection{Other therapies.}

The rational use of antivirals in randomized controlled trials reported being effective due to the urgency of the current situation. Antivirals, which have limited evidence that they may be, are common all over the world. It is used for the treatment of patients with SARS and influenza.

The data obtained suggest that it is more beneficial to start antiviral treatment early. It suggests. Therefore, one of the symptomatic patients diagnosed with possible COVID-19 compatible involvement with viral pneumonia in the chest x-ray or thorax CT imaging symptomatic with minimal fever symptoms diagnosed and diagnosed with definitive COVID19 Antiviral therapy was recommended to be started immediately in all patients. The combined use of antivirals in COVID-19 patients, patient-based, and existing all the literature should be considered and evaluated, the interactions of the drugs used, and care should be taken regarding the undesirable effects. Here, recommendations on antiviral treatment of COVID-19 are by evaluating evidence and ongoing clinical trial protocols evidence. In cases that are not available, it was created in line with the experts' opinions on the subject. According to the results of the studies to be published on antiviral treatment of COVID-19, these proposals will continue to be updated.

Systemic corticosteroids are not recommended for acute respiratory distress syndrome viral pneumonia treatment, among other therapeutic strategies. Despite no approved antiviral therapy, alpha-interferon (for example, twice per day 5 million units by aerosol inhalation) and lopinavir/ritonavir have been proposed. Preclinical studies suggest that remdesivir (GS5734), an RNA polymerase inhibitor with in vitro activity towards multiple RNA viruses embracing Ebola, can be influential for both prophylaxis and treatment of $\mathrm{HCoV}$ infections [44]. This drug was positively tested in a MERS-CoV infection rhesus macaque model [45]. Prone position ventilation may be recommended for those with poor results. Immune plasma therapy and stem cell therapy have been used as promising treatments in patients whose general condition has deteriorated and did not respond to treatment [46]. As COVID-19 is a newly encountered virus, no vaccine, monoclonal antibody, or drug directly affects it has been developed yet.

Although there are promising studies on vaccine and drug development, there is a high probability of not being completed for this pandemic period. Therefore, one of the fastest and easiest treatment options that first comes to mind and can directly target COVID-19 is to take serum or plasma from people who have survived this disease and are considered to contain antibodies against this virus and use it for both preventive and therapeutic purposes. Serum or plasma treatment has started to be easier and find application areas by increasing the number of those who survived the disease. Unlike the vaccine, this use falls into passive antibody therapy (PAT) and includes benefits and risks [47]. Considering the previous experience with plasma treatment, it seems to be the only available treatment option for the COVID-19 pandemic in today's conditions where vaccines and drugs could not be developed. One of the 
most important factors in the positive outcome of this treatment can be summarized as the presence of sufficient neutralizing antibodies in the transplanted plasma, and another is the rapid start of treatment of individuals with potential risk factors such as age. Briefly, since the immune systems of the recovered patients reacted differently to the virus, treatment should be directed considering the possibility of not having enough antibodies or not at all, if very few. In the treatment to be performed 1 week after the first plasma treatment, it is more appropriate to give the plasma of another donor or the plasma from a few donors to the patient rather than a donor. This is valid for the current situation, but it is expected that an efficacy test will be carried out before it is given for neutralization in the future [47]. PAT carries several risks. There may also be an increased risk of antibody-dependent viral infections, and its molecular mechanism is unknown. In addition, there is another risk that antibody therapy will suppress the development of acquired immunity. While this situation requires that the antibody level in the PAT treatment is sufficient until the disease is completely eliminated, it should be considered that an immune memory cannot be formed due to the metabolism of the externally given antibodies. Consequently, the vaccine should be taken into account after PAT. Besides, the duration of the plasma antibody and the effectiveness of the acquired immunity are also important as additional information. In this pandemic era, it is expected to pay attention to the vaccination of individuals who are not yet immune rather than vaccinating individuals who have naturally active antibody counts [46].

Scientists are working hard to determine the new coronavirus qualification and improve antivirus treatment and vaccines. Although the pathogenesis of the virus has not been elucidated yet, new studies are needed for this situation. Presently, the only path to avert the outspread of COVID-19 is an influential infection control method. The most appropriate treatment for patients under investigation identified with COVID-19 is still uncharted. Therefore, treatment protocols would be followed within the framework of existing health rules.

\section{Pediatric Patient Management and Treatment}

Concerning treatments for COVID-19 infection related to children, today, it is scientific. There is no data with sufficient evidence level. Therefore, COVID-19 for children's treatment recommendations should be evaluated according to adult studies and pediatric patients. It should be planned according to the situation. From the beginning of the COVID-19 outbreak, March 2020. To date, no deaths between the ages of 0-9 have been seen worldwide. Bigger $0.2 \%$ of deaths have been reported in children between the ages of 10-19. These figures and considering the shared data to date, the clinical picture in children appears to be mild. Also, the possible side effects of drugs in children should be considered when making treatment decisions. Treatment in childhood for today is every it should be evaluated separately for a patient and planned in possible severe cases (Table 1).

Table 1. Pediatric patient management and treatment.

\begin{tabular}{l|l|l} 
Medication name & $\begin{array}{l}\text { Daily child dosage and route of } \\
\text { administration }\end{array}$ & Treatment duration(days) \\
\hline Hydroxychloroquine, 200 mg tablet & $\begin{array}{l}\text { Hydroxychloroquine on the first day } \\
6.5 \mathrm{mg} / \mathrm{kg} / \text { dose } 2 \text { times a day sulfate; } \\
\text { maximum dose on the first day: } 400 \\
\mathrm{mg} / \text { dose; }\end{array}$ & 5 days
\end{tabular}




\begin{tabular}{l|l|l} 
Medication name & $\begin{array}{l}\text { Daily child dosage and route of } \\
\text { administration }\end{array}$ & Treatment duration(days) \\
\hline & $\begin{array}{l}\text { Hydroxychloroquine sulfate: } 2.5-3.25 \\
\mathrm{mg} / \mathrm{kg} / \mathrm{dose} 2 \text { times a day maximum } \\
\text { dose } 200 \mathrm{mg} / \mathrm{dose}\end{array}$ & \\
\hline Azithromycin $200 \mathrm{mg} / 5 \mathrm{ml}$ suspenders & $1-5$ months' children $10 \mathrm{mg} / \mathrm{kg} / \mathrm{dose}$ \\
& $\begin{array}{l}\text { (max dose } 500 \mathrm{mg} / \mathrm{dose})>6 \mathrm{months} \\
\text { children and adolescents } 10 \mathrm{mg} / \mathrm{kg} \text { first } \\
\text { day only dose (max dose } 500\end{array}$ & \\
& mg/dose) \\
& $\begin{array}{l}\text { Subsequently, } 5 \mathrm{mg} / \mathrm{kg} \text { once daily for } \\
2-5 \text { days. (max dose } 250 \mathrm{mg} / \mathrm{dose})\end{array}$ & \\
& total 5 days
\end{tabular}

On the other hand, the doctors use the Lopinavir $250 \mathrm{mg} /$ ritonavir 50mg tablet as an alternative treatment for 10-14 days. Both azithromycin and hydroxychloroquine prolong Q-T interval and tendency to ventricular tachycardia. Therefore, azithromycin should not be used especially in patients with another clinical condition that prolongs Q-T. In other cases, the patient can take ECG when necessary. The azithromycin must be discontinued in patients with cardiotoxic adverse effects, then the dose of hydroxychloroquine should be reduced first.

Furthermore, the safety, efficacy, and pharmacokinetics of lopinavir and ritonavir in newborns younger than 14 days' profiles are not determined. In newborns younger than 14 days, especially preterm propylene glycol toxicity in newborns using lopinavir/ritonavir oral solution, there is a risk of development. The oral solution includes ethanol and propylene glycol; ethanol propylene glycol competitively inhibits its metabolism. Early following the use of the oral solution, cardiotoxicity (bradycardia, complete AV block, cardiomyopathy), lactic acidosis, central nervous system depression, respiratory complications include acute kidney failure and death.

\section{Prevention}

Preventive measures are the present plan to reduce the prevalence of positions. As an outbreak will rise as long as the basic breeding number (R0) is greater than 1 (COVID-19 is 2.2), control measures should focus on decreasing the value to less than 1. Prophylactic approaches Taking appropriate precautions in the separation of patients on intensive and correct infection control, diagnosis, and providing medical care to an infected patient. For example, during sample collection, measures from droplets, contact, and air should be taken, and sputum induction should be avoided.

Presumably, transmission from children may be limited when premature closure of schools is coupled with reduced susceptibility to children. However, in milder or asymptomatic cases, the absence of a cough can reduce the transmission of the virus. More research is needed to test this belief.

\section{Future instructions}

Accurate pharmacokinetic, safety, and dosing data on the novel and redefined drugs for children, including the very young, should be provided.

A multipronged surveillance methodology could pave the way for advanced position determining and decreased transmission of highly infectious diseases such as COVID-19. 


\section{Conclusions}

The current study disclosed that transmission between persons in families, clinics, and express spread of the COVID-19 are highly potent, and hence vigilant control measures are critical at this early period of widespread. Scientists are working hard to determine the new coronavirus's characterization and improve antivirus treatment and vaccines. However, the pathogenesis of the virus is still not fully known, and new researches are required in this consider. Presently, the only path to avert the outspread of COVID-19 is an influential infection control method. The most appropriate treatment for patients under investigation diagnosed with COVID-19 is still unknown. Therefore, treatment protocols should be followed within the framework of existing health rules.

\section{Funding}

This research received no external funding.

\section{Acknowledgment}

This research has no acknowledgment.

\section{Conflicts of Interest}

The authors declare no conflict of interest.

\section{References}

1. Chan, J.F.-W.; Yuan, S.; Kok, K-H.; To, K.K.-W.; Chu, H.; Yang, J. A familial cluster of pneumonia associated with the 2019 novel coronavirus indicating person-to-person transmission: a study of a family cluster. Lancet 2020, 395, 514-523, https://doi.org/10.1016/S0140-6736(20)30154-9.

2. Wang, C.; Horby, P.W.; Hayden, F.G.; Gao, G.F. A novel coronavirus outbreak of global health concern. Lancet 2020, 395, 470-473, https://doi.org/10.1016/S0140-6736(20)30185-9.

3. Yang, J.; Zheng, Y.; Gou, X.; Pu, K.; Chen, Z.; Guo, Q. Prevalence of comorbidities in the novel Wuhan coronavirus (COVID-19) infection: a systematic review and meta-analysis. Int J Infect Dis 2020, 94, 91-95, https://doi.org/10.1016/j.ijid.2020.03.017.

4. Zhu, N.; Zhang, D.; Wang, W.; Li, X.; Yang, B.; Song, J.; Zhao, X.; Huang, B.; Shi, W.; Lu, R. A novel coronavirus from patients with pneumonia in China, 2019. N Engl J Med 2020, 382, 727-733, https://doi.org/10.1056/NEJMoa2001017.

5. Cui, J.; Li, F.; Shi, Z.L. Origin and evolution of pathogenic coronaviruses. Nat Rev Microbiol 2019, 17, 18192, https://doi.org/10.1038/s41579-018-0118-9.

6. Organization WH. WHO Director-General's remarks at the media briefing on 2019-nCoV on 11 February 2020. Available online: https://www.who.int/director-general/speeches/detail/who-director-general-sremarks-at-the-media-briefing-on-2019-ncov-on-11-february-2020 (accessed on 05 April 2021).

7. Munster, V.J.; Koopmans, M.; van Doremalen, N.; van Riel, D.; de Wit, E. A novel coronavirus emerging in China-key questions for impact assessment. $N$ Engl J Med 2020, 382, 692-694, https://doi.org/10.1056/NEJMp2000929.

8. Wu, F.; Zhao, S.; Yu, B.; Chen, Y.M.; Wang, W.; Song, Z.G.; Tao, Z.-W.; Tian, J.-H.; Pei, Y.-Y.; Yuan, M.L.; Zhang, Y.-L.; Dai, F.-H.; Liu, Y.; Wang, Q.-M.; Zheng, J.-J.; Xu, L; Holmes, E.C.; Zhang, Y.-Z. A new coronavirus associated with human respiratory disease in China. Nature 2020, 579, 265-269, https://doi.org/10.1038/s41586-020-2008-3.

9. Li, Q.; Guan, X.; Wu, P.; Wang, X.; Zhou, L.; Tong, Y.; Ren, R.; Leung, K.S.M.; Lau, E.H.Y.; Wong, J.Y. Early transmission dynamics in Wuhan, China, of novel coronavirus-infected pneumonia. $N$ Engl J Med 2020, 382, 1199-1207, https://doi.org/10.1056/NEJMoa2001316. 
10. Wen, F.; Yu, H.; Guo, J.; Li, Y.; Luo, K.; Huang, S. Identification of the hyper-variable genomic hotspot for the novel coronavirus SARS-CoV-2. J Infect 2020, 80, 671-693, https://doi.org/10.1016/j.jinf.2020.02.027.

11. Mullins, E.; Evans, D.; Viner, RM.; O’Brien, P.; Morris, E. Coronavirus in pregnancy and delivery: rapid review. Ultrasound Obstet Gynecol 2020, 55, 586-592, https://doi.org/10.1002/uog.22014.

12. Bialek, S.; Gierke, R.; Hughes, M.; McNamara, L.A.; Pilishvili, T.; Skoff, T. Coronavirus Disease 2019 in Children-United States, February 12-April 2, 2020. Morb Mortal Wkly Rep 2020, 69, 422-426, https://doi.org/10.15585/mmwr.mm6914e4.

13. Dong, Y.; Mo, X.; Hu, Y.; Qi, X.; Jiang, F.; Jiang, Z. Epidemiology of COVID-19 among children in China. Pediatrics 2020, 145, e20200702, https://doi.org/10.1542/peds.2020-0702.

14. Jeong, EK.; Park, O.; Park, YJ. COVID-19 National Emergency Response Center, Epidemiology and Case Management Team, Korea Centers for Disease Control and Prevention, Coronavirus disease-19: the first 7,755 cases in the Republic of Korea. Osong Public Heal Res Perspect 2020, 11, 85-90, https://doi.org/10.24171/j.phrp.2020.11.2.05.

15. Zhang, J.; Litvinova, M.; Liang, Y.; Wang, Y.; Wang, W.; Zhao, S.; Wu, Q.; Merler, S.; Viboud, C.; Vespignani, A.; Ajelli, M.; Yu, H. Changes in contact patterns shape the dynamics of the COVID-19 outbreak in China. Science 2020, 368, 1481-1486, https://doi.org/10.1126/science.abb8001.

16. Ai, T.; Yang, Z.; Hou, H.; Zhan, C.; Chen, C.; Lv, W.; Tao, Q.; Sun, Z.; Xia, L.. Correlation of chest CT and RT-PCR testing in coronavirus disease 2019 (COVID-19) in China: a report of 1014 cases. Radiology 2020, 296, E32-E40, https://doi.org/10.1148/radiol.2020200642.

17. Bai, H.X.; Hsieh, B.; Xiong, Z.; Halsey, K.; Choi, J.W.; Tran, T.M.L.; Pan, I.; Shi, L.-B.; Wang, D.-C.; Mei, J.; Jiang, X.-L.; Zeng, Q.-H.; Egglin, T.K.; Hu, P.-F.; Agarwal, S.; Xie, F.-F.; Li, S.; Healey, T.; Atalay, M.K.; Liao, W.-H. Performance of radiologists in differentiating COVID-19 from viral pneumonia on chest CT. Radiology 2020, 296, E46-E54, https://doi.org/10.1148/radiol.2020200823.

18. Demirtaş, T.; Tekiner, H. Filiation: A Historical Term the COVID-19 Outbreak Recalled in Turkey. Erciyes Med J 2020, 42, 54-358.

19. Phan, L.T.; Nguyen, T.V.; Luong, Q.C.; Nguyen, T.V.; Nguyen, H.T.; Le, H.Q. Importation and human-tohuman transmission of a novel coronavirus in Vietnam. $N$ Engl J Med 2020, 382, 872-874, https://doi.org/10.1056/NEJMc2001272.

20. Xie, X.; Zhong, Z.; Zhao, W.; Zheng, C.; Wang, F.; Liu, J. Chest CT for typical 2019-nCoV pneumonia: relationship to negative RT-PCR testing. Radiology 2020, 296, E41-E45, https://doi.org/10.1148/radiol.2020200343.

21. Wu, C.; Chen, X.; Cai, Y.; Zhou, X.; Xu, S.; Huang, H. Risk Factors Associated With Acute Respiratory Distress Syndrome and Death in Patients With Coronavirus Disease 2019 Pneumonia in Wuhan, China. JAMA Intern Med 2020, 180, 934-943, https://doi.org/10.1001/jamainternmed.2020.0994.

22. Xu, X.; Chen, P.; Wang, J.; Feng, J.; Zhou, H.; Li, X.; Zhong, W.; Hao, P. Evolution of the novel coronavirus from the ongoing Wuhan outbreak and modeling of its spike protein for risk of human transmission. Sci China Life Sci 2020, 63, 457-460, https://doi.org/10.1007/s11427-020-1637-5.

23. Kanne, J.P. Chest CT findings in 2019 novel coronavirus (2019-nCoV) infections from Wuhan, China: key points for the radiologist. Radiology 2020, 295, 16-17, https://doi.org/10.1148/radiol.2020200241.

24. Committee GO of NH. Office of State Administration of Traditional Chinese Medicine. Notice on the issuance of a program for the diagnosis and treatment of novel coronavirus (2019-nCoV) infected pneumonia (Trial Version 3). 2020.

25. Nishiura, H.; Jung, S.; Linton, NM.; Kinoshita, R.; Yang, Y.; Hayashi, K. The extent of transmission of novel coronavirus in Wuhan, China, 2020. J Clin Med 2020, 9, 330, https://doi.org/10.3390/jcm9020330.

26. Song, W.; Gui, M.; Wang, X.; Xiang, Y. Cryo-EM structure of the SARS coronavirus spike glycoprotein in complex with its host cell receptor ACE2. PLoS Pathog 2018, 14, e1007236, https://doi.org/10.1371/journal.ppat.1007236.

27. González, JM.; Gomez-Puertas, P.; Cavanagh, D.; Gorbalenya, AE.; Enjuanes, L. A comparative sequence analysis to revise the current taxonomy of the family Coronaviridae. Arch Virol 2003, 148, 2207-2235, https://doi.org/10.1007/s00705-003-0162-1.

28. Li, F. Structure, function, and evolution of coronavirus spike proteins. Annu Rev Virol 2016, 3, 237-261, https://doi.org/10.1146/annurev-virology-110615-042301.

29. Walls, A.C.; Tortorici, M.A.; Snijder, J.; Xiong, X.; Bosch, B.J.; Rey, F.A. Tectonic conformational changes of a coronavirus spike glycoprotein promote membrane fusion. Proc Natl Acad Sci 2017, 114, 11157-11162, https://doi.org/10.1073/pnas.1708727114. 
30. Millet, J.K.; Whittaker, G.R. Host cell proteases: Critical determinants of coronavirus tropism and pathogenesis. Virus Res 2015, 202, 120-134, https://doi.org/10.1016/j.virusres.2014.11.021.

31. Chen, N.; Zhou, M.; Dong, X.; Qu, J.; Gong, F.; Han, Y.; Qiu, Y.; Wang, J.; Liu, Y.; Wei, Y. Epidemiological and clinical characteristics of 99 cases of 2019 novel coronavirus pneumonia in Wuhan, China: a descriptive study. Lancet 2020, 395, 507-513, https://doi.org/10.1016/S0140-6736(20)30211-7.

32. Li, F. Receptor recognition mechanisms of coronaviruses: a decade of structural studies. J Virol 2015, 89, 1954-1964, https://doi.org/10.1128/JVI.02615-14.

33. Gui, M.; Song, W.; Zhou, H.; Xu, J.; Chen, S.; Xiang, Y.; Wang, X. Cryo-electron microscopy structures of the SARS-CoV spike glycoprotein reveal a prerequisite conformational state for receptor binding. Cell Res 2017, 27, 119-129, https://doi.org/10.1038/cr.2016.152.

34. Chu, DKW.; Pan, Y.; Cheng, S.; Hui, KPY.; Krishnan, P.; Liu, Y. Molecular diagnosis of a novel coronavirus (2019-nCoV) causing an outbreak of pneumonia. Clin Chem 2020, 66, 549-555, https://doi.org/10.1093/clinchem/hvaa029.

35. Shang, J.; Wan, Y.; Liu, C.; Yount, B.; Gully, K.; Yang, Y.; Auerbach, A.; Peng, G.; Baric, R.; Li, F. Structure of mouse coronavirus spike protein complexed with receptor reveals mechanism for viral entry. PLoS Pathog 2020, 16, e1008392, https://doi.org/10.1371/journal.ppat.1008392.

36. Mao, L.; Jin, H.; Wang, M.; Hu, Y.; Chen, S.; He, Q.; Chang, J.; Hong, C.; Zhou, Y.; Wang, D.; Miao, X.; Li, Y.; Hu, B. Neurological Manifestations of Hospitalized Patients with COVID-19 in Wuhan, China: a retrospective case series study, JAMA Neurology 2020, https://doi.org/10.1001/jamaneurol.2020.1127.

37. Baig, AM.; Khaleeq, A.; Ali, U.; Syeda, H. Evidence of the COVID-19 Virus Targeting the CNS: Tissue Distribution, Host-Virus Interaction, and Proposed Neurotropic Mechanisms. ACS Chem. Neurosci 2020, 11, 995-998, https://dx.doi.org/10.1021/acschemneuro.0c00122.

38. Lillie, P.J.; Samson, A.; Li, A.; Adams, K.; Capstick, R.; Barlow, G.D.; Easom, N.; Hamilton, E.; Moss, P.J.; Evans, A. Novel coronavirus disease (Covid-19): the first two patients in the UK with person to person transmission. J Infect 2020, 80, 578-606, https://dx.doi.org/10.1016/j.jinf.2020.02.020.

39. Wrapp, D.; Wang, N.; Corbett, K.S.; Goldsmith, J.A.; Hsieh, C.-L.; Abiona, O.; Graham, B.S.; McLellan, J.S. Cryo-EM structure of the 2019-nCoV spike in the prefusion conformation. Science 2020, 367, 12601263, https://doi.org/10.1126/science.abb2507.

40. Yan, R.; Zhang, Y.; Guo, Y.; Xia, L.; Zhou, Q. Structural basis for the recognition of the 2019-nCoV by human ACE2. BioRxiv 2020, https://doi.org/10.1101/2020.02.19.956946.

41. Tian, S.; Hu, W.; Niu, L.; Liu, H.; Xu, H.; Xiao, S.Y. Pulmonary pathology of early phase 2019 novel coronavirus (COVID-19) pneumonia in two patients with lung cancer. J Thorac Oncol 2020, 15, 700-704, https://doi.org/10.1016/j.jtho.2020.02.010.

42. Ng, Y.; Li, Z.; Chua, Y.X.; Chaw, W.L.; Zhao, Z.; Er, B.; Pung, R.; Chiew, C.J.; Lye, D.C.; Heng, D. Evaluation of the effectiveness of surveillance and containment measures for the first 100 patients with COVID-19 in Singapore-January 2-February 29, 2020. Center for Disease Control and Prevention 2020, 69, 307-311, http://dx.doi.org/10.15585/mmwr.mm6911e1.

43. Cascella, M.; Rajnik, M.; Cuomo, A.; Dulebohn, S.C.; Di Napoli, R. Features, Evaluation and Treatment Coronavirus (COVID-19). StatPearls [Internet], StatPearls Publishing 2020.

44. Gordon, C.J.; Tchesnokov, E.P.; Feng, J.Y.; Porter, D.P.; Gotte, M. The antiviral compound remdesivir potently inhibits RNA-dependent RNA polymerase from Middle East respiratory syndrome coronavirus. $J$ Biol Chem 2020, 295, 4773-4779, http://dx.doi.org/10.1074/jbc.AC120.013056.

45. de Wit, E.; Feldmann, F.; Cronin, J.; Jordan, R.; Okumura, A.; Thomas, T.; Scott, D.; Cihlar, T.; Feldmann, H. Prophylactic and therapeutic remdesivir (GS-5734) treatment in the rhesus macaque model of MERS-CoV infection. Proc Natl Acad Sci 2020, 117, 6771-6776, https://doi.org/10.1073/pnas.1922083117.

46. Turkish Ministry of Health. Available online: https://covid19bilgi.saglik.gov.tr/tr/tedavi (accessed on 2 May 2020).

47. Abdullah, U.; Arslan, Ş.; Manap, H.S.; Gürkan, T.; Çalişkan, M.; Dayioğlu, A.; Efe, H.N.; Yilmaz, M.; İbrahimoğlu, A.Z.; Gültekin, E. Türkiye'de Covid-19 Pandemisinin Monitörizasyonu Için Interaktif Ve Gerçek Zamanlı Bir Web Uygulaması: TURCOVID19. Anadolu Klin Tıp Bilim Derg 2020, 25, 154-155, https://doi.org/10.21673/anadoluklin.726347. 